\title{
Concentration Risk Indicator
}

\author{
Anis Hadzisalihovic, Johann Pruckner, Andreas Kern \\ Erste Asset Management GmbH, Vienna, Austria \\ Email: anis.hadzisalihovic@erste-a m.com, johann.pruckner@erste-am.com, andreas.kern@erste-am.com
}

How to cite this paper: Hadzisalihovic, A., Pruckner, J., \& Kern, A. (2019). Concentration Risk Indicator. Journal of Financial Risk Management, 8, 92-105. https://doi.org/10.4236/jfrm.2019.82007

Received: April 29, 2019

Accepted: June 17, 2019

Published: June 20, 2019

Copyright () 2019 by author(s) and Scientific Research Publishing Inc. This work is licensed under the Creative Commons Attribution International License (CC BY 4.0).

http://creativecommons.org/licenses/by/4.0/

(c) (i) Open Access

\begin{abstract}
In common portfolio theory ${ }^{1}$, a significant reduction of risk is expected when investments are split into two or more positions. A lower correlation between positions results in a higher risk-reducing portfolio effect. The credit risk of a portfolio is dependent on the default risk of all its issuers. By investing in two different debtors instead of only one, the probability of the total loss is significantly reduced and a debtor concentration is prevented. Concentration risk can be reduced by diversifying the portfolio. How can concentration risk be defined in a quantitative way? The aim of this paper is to determine a key figure, which makes concentration risk measurable.
\end{abstract}

\section{Keywords}

Issuer Concentration, Diversification, Rating, Default Probability

\section{Introduction}

One of the consequences of the 2008 financial crisis was that both investors and regulators placed a greater focus on risk management. In particular, the reorganization of the legal framework increasingly required risk limits to be determined and monitored. An essential prerequisite for this is the quantification of risks. The existing literature ${ }^{2}$ is only partially helpful in doing so.

For instance, whereas the measurement of market risk, usually defined as a second moment i.e. expected volatility or value at risk, is widely discussed and documented among experts, concentration risk is underrepresented in the literature for the specific demands of investment companies. For this reason, a need

${ }^{1}$ Optimising portfolio selection (Marling and Emanuelsson, 2012: pp. 1-6).

${ }^{2} 1$ ) Corporate Governance of Banks after the Financial Crisis-Theory, Evidence, Reforms (Mlbert, 2010: pp. 24-30). 2) Eu Financial Market Regulation after the Global Financial Crisis: "More Europe "or more Risks? (Moloney, 2010: pp.1325-1378). 3) Lessons From The 2008 Global Financial Crisis: Imprudent Risk Management And Miss Calculated Regulation (Vo, 2015: pp. 205-219). 
has arisen for a new measure of concentration risk to be developed.

A more detailed overview of concentration risk and its measurement will be presented after this short introduction.

\section{Existing Concentration Measures}

A common approach for measuring concentrations is the Herfindahl-Index $(\mathrm{HI})^{3}$.

The HI is one of the most known ratios for measuring the concentration of a variable distributed over a certain number of units (Gioia, 2017: pp. 1-2), and design to measure the degree of market concentration of a particular industry (Bank, 2018: pp. 17-18), (Naldi \& Naldi, 2014: pp. 2-4). A good, exact explanation of the HI with different parameters can be found in a paper from the authors Naldi and Flamini (Naldi \& Flamini, 2017: pp. 3-8).

The HI is determined from the quotient of the sum of the individual characteristic value squared, divided by the square of the sum of the individual characteristic values (Semper \& Beltrn, 2011: pp. 1768-1770), (Tasche, 2006: pp. 15-16), (Watt \& Quinto, 2003: pp. 6-8):

$$
H I=\frac{\sum_{i=1}^{n} V_{i}^{2}}{\left(\sum_{i=1}^{n} V_{i}\right)^{2}}
$$

where:

$n \quad$ number of positions

$V_{i} \quad$ amount or percentage of the characteristic value

$V_{1}, V_{2}, \ldots, V_{n}$ can be, for example, not only the individual companies of an equity portfolio, but also sub-quantities such as all equities of a particular region or sector.

The smaller the HI value, the higher the diversification in the portfolio. The index assumes values between 0 and 1 . The limitation is defined as:

$$
0 \leq H I \leq 1
$$

The $H I$ value of two positions, each with $50 \%$ weights in the portfolio, gives $\frac{0.25+0.25}{1}=0.5$

For 10 equally weighted positions, the value is $\frac{10 \cdot 0.01}{1}=0.1$.

Depending on which characteristic value is measured (individual positions, ratings, region, industry, sector, ...), different $\mathrm{HI}$ values are produced. The selection of the characteristic value therefore ultimately decides the result.

Reynolds' conclusion states that the HI "provides different results for the same portfolio depending upon the dimension measured and it fails to provide any actionable information" (Reynolds, 2009: p. 7), however, it is also noticed in practice.

${ }^{3}$ The Herfindahl-Index "is a statistical measure of concentration" (Rhoades, 1993: p. 188). 
Beyond the fundamental question of selecting the individual characteristic value, the restriction of using a single dimension often pushes the concept of the HI to its limits in practice.

More complex questions cannot be answered with the HI, such as the concentration in bond portfolios which also considers credit quality of issuers in addition to the number or weights of issuers, perceived as multi-dimensional.

It seems intuitively understandable that, for a bond portfolio, issuer concentrations vary depending on whether the credit quality of each issuer is high or low. For example, the question arises whether a portfolio made up of four AAA issuers would be more problematic in terms of concentration than a portfolio of eight $\mathrm{BB}$ issuers, as the $\mathrm{HI}$ would indicate. For this reason, $\mathrm{HI}$ is not suitable for the problem of multidimensionality. Nevertheless, HI is highly suited for calculating the concentration of equities, as the characteristics of each equity are almost all uniform.

A quantitative approach to this multi-dimensional problem can be formulated with methods of probability theory. If a portfolio consists of n-equally-weighted issuers with an identical default probability $p$, the possible change in the portfolio value due to credit losses follows a random distribution. In the simplest case, there are only two possible events with a single issuer.

- A $100 \%$ failure with probability $p$.

- No failure i.e. no change in the portfolio value with the probability $\mathrm{p}-1$.

As the number of issuers increases, the number of possible outcomes increases.

For 10 issuers, $1,2, \ldots \ldots \ldots, 10$ issuers can default and the portfolio value would decrease by $10 \%, 20 \%$, $100 \%$.

The change of the portfolio value is binomially distributed with the parameters:

- $n \quad$ number of trials, i.e. number of issuers.

- $p$ default probability of the issuer.

In the example of ten equally weighted issuers with an identical probability of default, the use of the binomial distribution yields the following results as illustrated in Table 1.

The first two moments of the binomial distribution are defined as follows:

$$
\begin{gathered}
E(X)=p_{\tau} \\
\operatorname{Var}(X)=\underbrace{p_{\tau}}_{E(X)} * \frac{1-p_{\tau}}{n} \\
\sigma(X)=\sqrt{\operatorname{Var}(X)}
\end{gathered}
$$

where:

$$
\begin{array}{ll}
E & \text { expected value. } \\
\mathrm{X} & \text { default risk of the portfolio. } \\
p_{\tau} & \text { default probability of an issuer over the period } T . \\
\operatorname{Var} & \text { variance. } \\
n & \text { number of issuers. } \\
\sigma & \text { standard deviation. }
\end{array}
$$


Table 1. Binomial distribution, $n=10, p=1 \%$.

\begin{tabular}{ccc}
\hline Defaults & Portfolio value change & Probability $^{\mathrm{a}}$ \\
\hline 0 & $0 \%$ & $90.44 \%$ \\
1 & $-10 \%$ & $9.14 \%$ \\
2 & $-20 \%$ & $0.42 \%$ \\
3 & $-30 \%$ & $0.01 \%$ \\
4 & $-40 \%$ & $0.00 \%$ \\
5 & $-50 \%$ & $0.00 \%$ \\
6 & $-60 \%$ & $0.00 \%$ \\
7 & $-70 \%$ & $0.00 \%$ \\
8 & $-80 \%$ & $0.00 \%$ \\
9 & $-90 \%$ & $0.00 \%$ \\
10 & $-100 \%$ & $0.00 \%$ \\
\hline
\end{tabular}

a BINOMDIST is a binomial distribution function. (Koshti, 2017: p. 8), (The Binomial Distribution, 2018: pp. 2-11), (Habibi \& Asgharzadeh, 2017: pp. 2-19) with the following parameters: 1) Number: Defaults; 2) Trials: Total number of defaults; 3) Probability: 99\%; 4) Cumulative: 0.

As can be seen from the above equations, the expected value of defaults is invariant to the number of issuers, while the standard deviation decreases as the number of issuers increase.

For example, to calculate the issuer $n-$ with the given variables:

- standard deviation $\sigma(X)=1.41 \%$ and

- default probability of an issuer over the period $T p_{\tau}=1 \%$.

The second (2) equation and third (3) equation (as written above) need to be rearranged to achieve the variable $n$

$$
n=\frac{p_{\tau}\left(1-p_{\tau}\right)}{\operatorname{Var}(X)}=\frac{1 \% *(1-1 \%)}{(1.41 \%)^{2}}=50 .
$$

The consequences of a different standard deviation due to the different number of issuers are shown in the following graphs, Figure 1 and Figure 2. They show the possible changes in the portfolio value due to the defaults in a portfolio of 10 issuers on the one hand and 50 issuers on the other hand.

The probability of losing $10 \%$ due to defaults is $9.14 \%$ for a portfolio of 10 issuers is illustrated in Figure 1. The individual steps of the calculation are shown in Table 1.

For a portfolio of 50 issuers to lose $10 \%$ requires five issuers to default.

The probability of this is only $0.01 \%$. See Table 2 for an explanation of the Figure 2.

In principle, the use of the binomial distribution can be of significant help in defining quantitative guidelines regarding the concentration of bond portfolios. For example, it is conceivable that a portfolio must be diversified to an extent that the probability of loss due to defaults cannot exceed $\mathrm{x} \%$. 


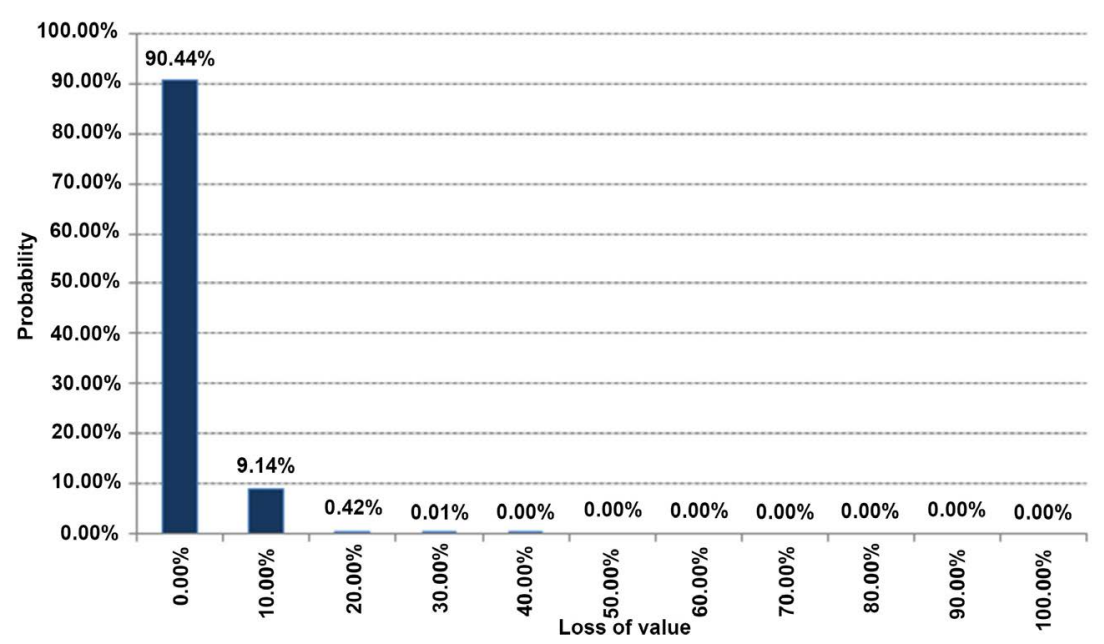

Figure 1. Binomial distribution, $\mathrm{n}=10, \mathrm{p}=1 \%$.

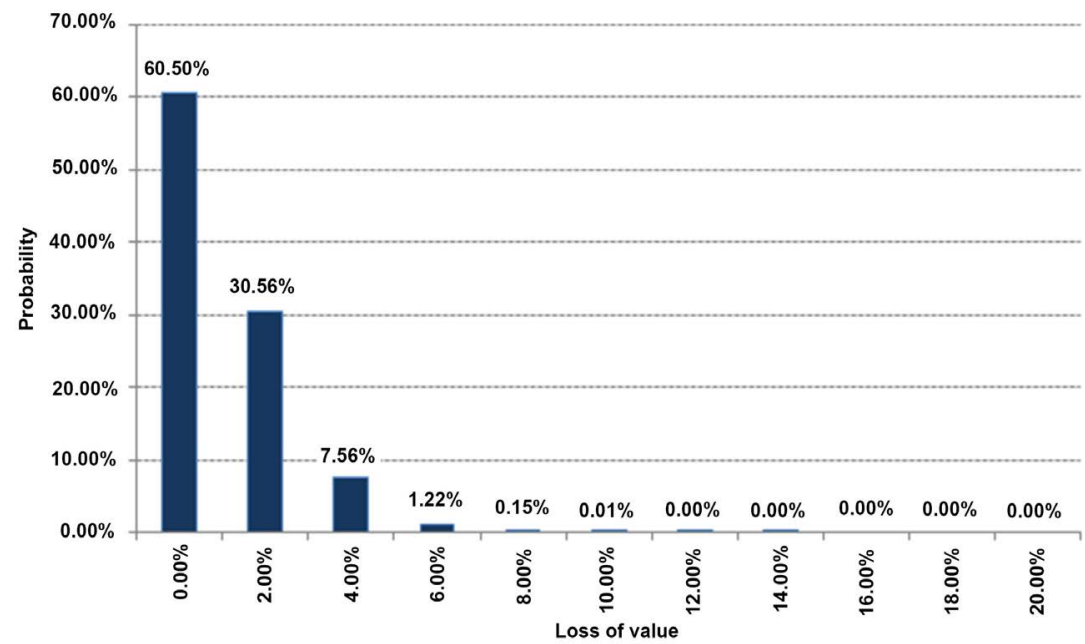

Figure 2. Binomial distribution, $\mathrm{n}=50, \mathrm{p}=1 \%$.

However, the applicability of this methodology, as presented so far, is dependent on three main limiting assumptions:

1) the weights of the issuers are identical

2) the default probabilities of all issuers are identical

3) the defaults of issuers are independent on each other

Only in the rarest of cases these assumptions are applicable in practice.

The rating agency Moody's has developed a methodology called Binomial Expansion Technique (BET) to abandon the restrictive assumptions of identical weights and default probabilities or uncorrelated default events and is still able to use binomial distribution in the valuation of CDOs. The complexity of the algorithm used by Moody's makes it impractical to describe it in detail in the context of this paper and therefore a reference is made to the relevant literature ${ }^{4}$.

In essence, the approach can be summarized as follows:

${ }^{4}$ Moody's Approach To Rating Synthetic CDOs BIS Working Papers No. 163, CDO rating methodology: Some thoughts on model risk and its implications (Yoshizawa \& Witt, 2003: pp. 1-24). 
Table 2. Binomial distribution, $\mathrm{n}=50, \mathrm{p}=1 \%$.

\begin{tabular}{ccc}
\hline Defaults & Portfolio value change & Probability $^{\mathrm{b}}$ \\
\hline 0 & $0 \%$ & $60.50 \%$ \\
1 & $-2 \%$ & $30.56 \%$ \\
2 & $-4 \%$ & $7.56 \%$ \\
3 & $-6 \%$ & $1.22 \%$ \\
4 & $-8 \%$ & $0.15 \%$ \\
5 & $-10 \%$ & $0.01 \%$ \\
6 & $-12 \%$ & $0.00 \%$ \\
7 & $-14 \%$ & $0.00 \%$ \\
8 & $-16 \%$ & $0.00 \%$ \\
9 & $-18 \%$ & $0.00 \%$ \\
10 & $-20 \%$ & $0.00 \%$ \\
$\cdot$ & $\cdot$ &. \\
$\cdot$ & $\cdot$ &. \\
50 & $-100 \%$ & $0.00 \%$ \\
\hline
\end{tabular}

${ }^{\mathrm{b}}$ BINOMDIST is a binomial distribution function (Koshti, 2017: p. 8), (The Binomial Distribution, 2018: pp. 2-11), (Habibi \& Asgharzadeh, 2017: pp. 2-19) with the following parameters: 1) Number: Defaults; 2) Trials: Total number of defaults; 3) Probability: 99\%; 4) Cumulative: 0.

The objective of the approach is to calculate the expected loss of a portfolio and to assign a corresponding rating to that portfolio. As mentioned above, in order to apply the binomial distribution, Moody's transforms an existing portfolio of issuers of different ratings, weights and dependencies into a synthetic portfolio that meets the conditions for applying the binomial distribution. The transformation of different default probabilities into a single one for the overall portfolio is not particularly difficult and can easily be accomplished by establishing a weighted average ${ }^{5}$. In order to calculate the distribution of the expected losses, it is necessary to have-in addition to the probability of default-the input factor of the number of issuers or, in the terminology of the binomial distribution, the number of trials (n).

Moody's algorithm makes it possible to calculate a synthetic number of issuers with the same weights from a portfolio with different weights of issuers of different credit qualities. This value, which Moody's calls the Alternative Diversity Score (ADS) (Fender \& Kiff, 2004: pp. 4-5), may in some cases coincide with the actual number of issuers but generally differs from the actual number of issuers. The exact formula for ADS does not play a significant role in this paper, but is of great importance for the following line of reasoning (Fender \& Kiff, 2004: pp. 4-5):

$$
A D S=\frac{\left(\sum_{i=1}^{n} p_{i} F_{i}\right) *\left(\sum_{i=1}^{n}\left(1-p_{i}\right) F_{i}\right)}{\sum_{i=1}^{n} \sum_{j=1}^{n} \rho_{i j}\left(p_{i}\left(1-p_{i}\right) p_{j}\left(1-p_{j}\right)\right)^{\frac{1}{2}} F_{i} F_{j}}
$$

${ }^{5}$ WARF method according to Moody's. 
where:

$F_{i, j} \quad$ size of $i$ and $j$ position

$n \quad$ number of positions

$p_{i} \quad$ default probability of position $i$

$\rho_{i j} \quad$ pairwise default correlations

If it is assumed for a moment that the default probability of all issuers is identical, then the formula is reduced to (Waibel, 2006: pp. 32-38):

$$
A D S=\frac{\sum_{i=1}^{n} F_{i}^{2}}{\sum_{i=1}^{n} \sum_{j=1}^{n} Q_{i j} F_{i} F_{j}}
$$

where:

$Q_{i j} \quad$ correlation matrix.

In this case, the ADS is completely independent of the default probability. Two portfolios with different probability of default will-ceteris paribus-have the same diversity score.

If the ADS is used as a measure of concentration, it would have the same value for a portfolio of $10 \mathrm{AAA}$ issuers as for a portfolio of $10 \mathrm{BB}$ issuers.

The basic idea of demanding a higher diversification from a portfolio with lower credit quality and correspondingly assigning a different degree of concentration is therefore not appropriate for the ADS. Its true purpose is solely as an input factor for the Moody's binomial-based rating approach.

Both the HI and Moody's ADS are of limited suitability in assigning a measure of diversification or concentration for the purpose of bond portfolios and making the portfolios directly comparable, taking into account both weights and default probabilities of issuers.

An alternative to the existing concentration risk indicators is presented below.

\section{Concentration Risk Indicator}

This newly developed concentration ratio identifies potential concentration risks for positions that are not evenly built up in the portfolio. The measure is characterised by the fact that it focuses not only on the relative weights of issuers but also on their credit quality.

\subsection{Initial Value}

As a first step, it is to be assumed that a portfolio consists $100 \%$ of bonds issued by a single issuer. For an issuer with a very high credit quality (e.g. Germany or the USA) the concentration risk indicator is 0 due to the low probability of default, even when the issuer weight is $100 \%$. As credit quality declines, the concentration indicator would increase exponentially when the issuer weight is $100 \%$.

This relationship can be represented in an exponential function ${ }^{6}$ of the following form, as illustrated in Figure 3:

"exponential function $f(x)=e^{x}$ is the fact that the exponential function is the only nontrivial solution of the differential equation $f^{\prime}=f$ " (Alsina \& Ger, 1998: pp. 373-374). 


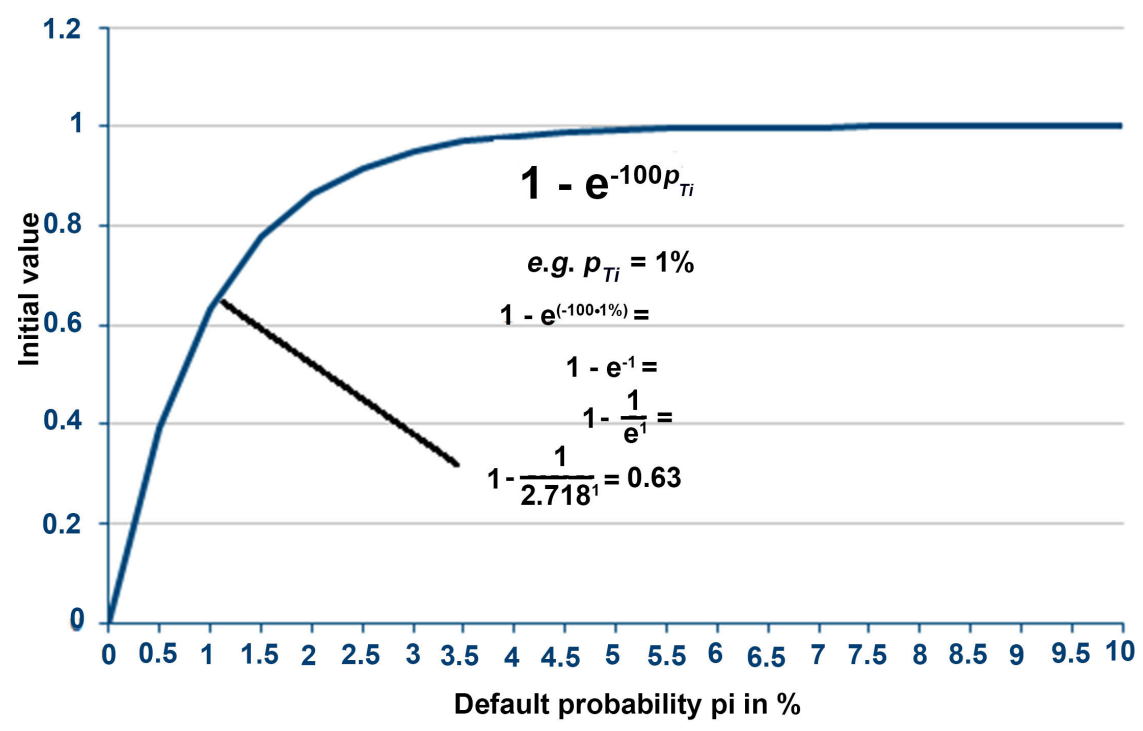

Figure 3. Single issuer portfolio and default probability $p_{i}$ in $\%$.

$$
1-\mathrm{e}^{-100 p_{T i}}
$$

$p_{T i}$ is the default probability of a rating category $i$ for the period $T$.

In the case where the $p_{T i}$ is 0 , the concentration indicator assumes a value of 0 . As the default risk increases, the indicator approaches a value of 1 .

A portfolio of, for example, $100 \%$ German government bonds would imply a concentration risk indicator of approximately 0 , meaning the high credit quality of the issuer, Germany, would completely compensate for the $100 \%$ weight of the portfolio concentration.

\subsection{Diversification Factor}

As a next step, a 1-issuer portfolio is no longer assumed and the concentration risk indicator is reduced by diversification. The concentration risk indicator thus decreases as the number of issuers increases, as shown in Figure 4.

The diversification factor $(D F)$ is defined by the following equation:

$$
D F=\alpha^{-100 * \frac{\frac{1}{w_{i}}-1}{n_{i}}}
$$

where:

$w_{i} \quad$ issuer weight of the portfolio, given that $0 \leq w_{i} \leq 1$.

$n_{i} \quad$ required number of issuers, to be determined by risk preferences, e.g. the $\mathrm{BB}$ rating requires 100 issuers.

$\alpha$ diversification decay factor, given that $0 \leq a \leq \infty$.

The value of $\alpha$ determines the "speed" of diversification, i.e. the gradient of the diversification curve, as illustrated in Figure 4.

Input factors are, on the one hand, the required number of bonds $n_{i}$ and, on the other hand, the actual weights of a bond $w_{i}$. 


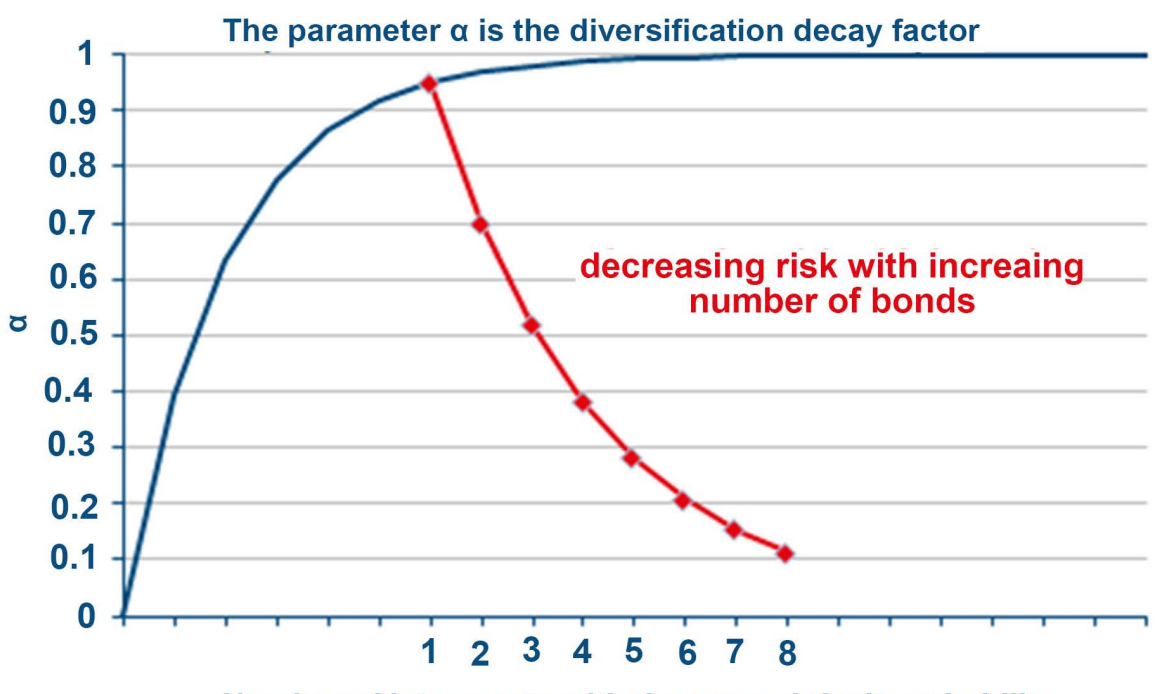

Number of intruments with the same default probability

Figure 4. Reduction of the concentration risk indicator through diversification.

The exponent $-100 * \frac{\frac{1}{w_{i}}-1}{n_{i}}$ expresses the ratio of actual weights and target weights.

This calculation is carried out for each issuer and, as such, a concentration risk indicator value is generated for each individual issuer. The concentration risk indicator contribution for the overall portfolio is established by multiplying the concentration risk indicator value by the weights of the issuer, and the sum of these contributions gives the overall concentration risk indicator.

The concentration risk indicator $(C R I)$ is thus defined as:

$$
C R I=\sum_{i=1}^{N} \underbrace{\left(1-\mathrm{e}^{-10 p_{p_{T i}}}\right)}_{\text {Initial Value }} * \overbrace{w_{i}}^{\text {Weight }} * \underbrace{\alpha^{-100 * \frac{1}{w_{i}}-1} n_{i}}_{\text {Diversification }}
$$

where:

$$
\begin{aligned}
& N=\quad \text { number of issuers } \\
& \alpha=\quad \text { diversification decay factor } \\
& p_{T i}=\text { default probability of a rating category } i \text { for the period } T i \text { given that } \\
& 0<p_{T i} \leq 1 \\
& w_{i}=\quad \% \text { weight of an issuer } i \text { in a portfolio given that } 0<w_{i} \leq 1 \\
& n_{i}=\quad \text { required number of issuers } i \text { dependent on the rating } \\
& e=\quad \text { euler number with } 2.718^{7}
\end{aligned}
$$
signals a high concentration risk.

CRI acknowledges the fact that low ratings generally require high diversification, e.g. an instrument with an AAA rating does not need to be diversified,

${ }^{7}$ The euler number is described in (Tognetti, 1998: pp. 2-3), (Qi, Niu, \& Guo, 2017: pp. 1-7). 
whereas an instrument with a $\mathrm{BB}$ rating should be diversified. A portfolio with four BB-rated bonds has a lower CRI than a portfolio with three BB-rated bonds.

\section{Practical Example}

As a practical example, data from the bond portfolio described in Table 3 will be used to calculate a CRI ratio.

The steps involved in calculating the CRI ratio are enumerated below:

- Step 1: As there are two identical issuers, the weights for the Polish issuers will be added together, as specified in Table 4 .

- Step 2: A rating is assigned to each issuer.

- Step 3: A probability of default $p$ must be assigned to each rating as specified by Moody's credit rating.

- Step 4: Determine the Initial Value as in Table 4.

- Step 5: Determine the number of issuers $n_{i}$ as in Table $4^{8}$.

- Step 6: Determine the diversification factor $D F$, with $\alpha=1.05$ as in Table 4.

- Step 7: Calculate CRI for each issuer as in Table 5.

- Step 8: Add all the $C R I$ values together to get the $C R I$ ratio total for the portfolio as in Table 5.

The $C R I$ ratio for this example is 0.58 . As mentioned, the CRI ranges from 0 to 1 . Algorithm 1 shown below explains in detail the steps involved in calculating the CRI ratio:

Algorithm 1. Pseudocode for calculating CRI.

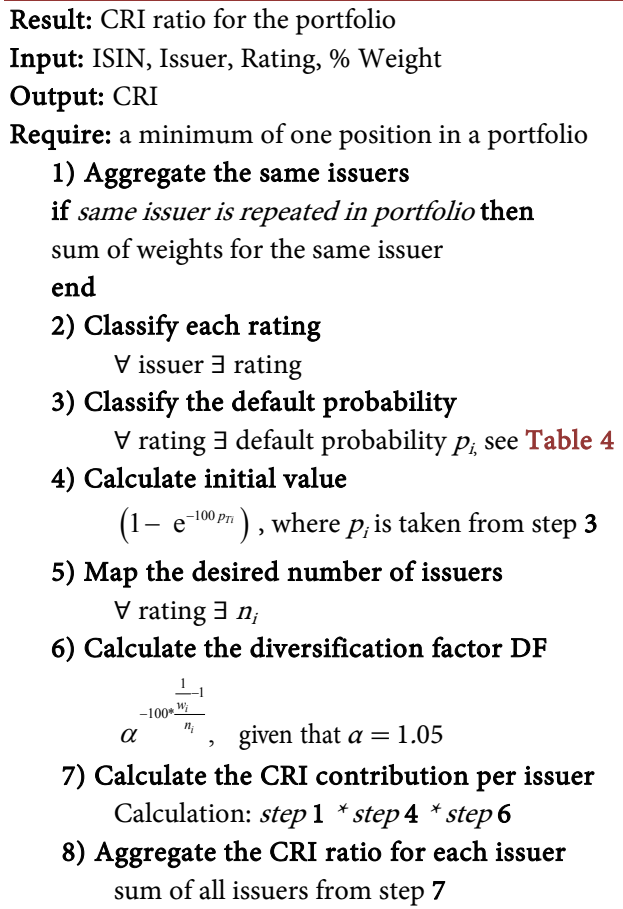

${ }^{8} n_{i}$ is freely selectable-better ratings result in a smaller number of required issuers and worse ratings result in a larger number of required issuers. 
Table 3. Portfolio data example.

\begin{tabular}{ccccc}
\hline Type & ISIN & Issuer & Rating & $\%$ Weight \\
\hline Bond & TRT150120T16 & Turkey & BB+ & 18.79 \\
Bond & HU0000402037 & Hungary & BBB- & 9.45 \\
Bond & CZ0001002851 & Czech & A+ & 15.63 \\
Bond & XS0638572973 & Capital & BB+ & 10.00 \\
Bond & PL0000106670 & Poland & A- & 20.85 \\
Bond & XS0767473852 & Russia & BB+ & 5.35 \\
Bond & XS0800817073 & VEB Fin. & BB+ & 4.32 \\
Bond & XS0841073793 & Poland & A- & 7.96 \\
Bond & XS1028953989 & Croatia & BB & 5.34 \\
Bond & XS1403619411 & Krajo & A- & 2.31 \\
\hline
\end{tabular}

Source: Erste Asset Management database, May 2018.

Table 4. Constituents of the CRI calculation.

\begin{tabular}{ccccccc}
\hline Issuer & \% Weight & Rating & $p$ & Initial Value & $n_{i}$ & $D F$ \\
\hline Turkey & 18.79 & $\mathrm{BB}+$ & 9.4 & 1.00 & 121 & 0.84 \\
Hungary & 9.45 & $\mathrm{BBB}-$ & 6.1 & 1.00 & 100 & 0.63 \\
Czech & 15.63 & $\mathrm{~A}+$ & 0.7 & 0.50 & 25 & 0.35 \\
Capital & 10.00 & $\mathrm{BB}+$ & 9.4 & 1.00 & 121 & 0.70 \\
Poland & 28.81 & $\mathrm{~A}-$ & 1.8 & 0.83 & 49 & 0.78 \\
Russia & 5.35 & $\mathrm{BB}+$ & 9.4 & 1.00 & 121 & 0.49 \\
VEB Fin. & 4.32 & $\mathrm{BB}+$ & 9.4 & 1.00 & 121 & 0.41 \\
Croatia & 5.34 & $\mathrm{BB}$ & 13.5 & 1.00 & 144 & 0.55 \\
Krajo & 2.31 & $\mathrm{~A}-$ & 1.8 & 0.83 & 49 & 0.01 \\
\hline
\end{tabular}

Table 5. CRI calculation for the portfolio.

\begin{tabular}{cc}
\hline Issuer & CRI \\
Turkey & 0.16 \\
Hungary & 0.06 \\
Czech & 0.03 \\
Capital & 0.07 \\
Poland & 0.19 \\
Russia & 0.03 \\
VEB Fin. & 0.02 \\
Croatia & 0.03 \\
Krajo & 0.00 \\
Total & 0.58 \\
\hline
\end{tabular}




\section{Summary}

Various techniques for measuring, assessing and presenting concentration risks have been presented, and it has been determined that using existing scientific methods can produce misleading results.

In assessing concentration risks in bond portfolios, there is a two-dimensional problem insofar as the weight and credit quality of an issuer must be taken into account. For example, two portfolios that have the same number of issuers and equal weights but different issuer credit quality will have to be assessed differently in regards to their concentration risk.

This paper presents a credit risk adjusted diversification measure that is suitable for concentration risk assessment of bond portfolios using a single number, taking into account both weight and credit quality. CRI allows the identification of possible concentration risks within a large group of portfolios. Due to the standardised approach, CRI enables us to compare the concentration risk of different portfolios.

Further research is required regarding the suitability of CRI for estimating the loss variance of a portfolio under stressed credit market conditions. The research thus far neither considered correlations between bonds in the portfolios, nor showed how it is expected to impact of portfolio return. Empirical evidence is therefore necessary concerning the input factor for loss estimation of CRI in comparison with approaches like the Herfindahl-Index and WARF and their corresponding ratios.

\section{Conflicts of Interest}

The authors declare no conflicts of interest regarding the publication of this paper.

\section{References}

Alsina, C., \& Ger, R. (1998). On Some Inequalities and Stability Results Related to the Exponential Function. Journal of Inequalities and Applications, 2, 337-380. https://doi.org/10.1155/S102558349800023X http://www.kurims.kyoto-u.ac.jp/EMIS/journals/HOA/JIA/2/4373.pdf

Bank, St. Louis (2018). Simulation of the Hirfindahl-Hirschman Index: The Case of the St. Louis Banking Geographic Market. http://www.siue.edu/GEOGRAPHY/ONLINE/zhou3.pdf

Fender, I., \& Kiff, J. (2004). CDO Rating Methodology: Some Thoughts on Model Risk and Its Implications (p. 23). BIS Working Papers No. 163. https://www.bis.org/publ/work163.pdf https://doi.org/10.2139/ssrn.623662

Gioia, G. (2017). A Decomposition of the Herfindahl Index of Concentration. https://mpra.ub.uni-muenchen.de/82944

Habibi, M., \& Asgharzadeh, A. (2017). Power Binomial Exponential Distribution: Modeling, Simulation and Application. Communications in Statistics-Simulation and Computation, 47, 3042-3061. http://www.tandfonline.com/loi/lssp20

Koshti, A. M. (2017). Optimizing Probability of Detection Point Estimate Demonstration. 
In SPIE Smart Structures/NDE 2017 (pp. 1-28).

https://ntrs.nasa.gov/archive/nasa/casi.ntrs.nasa.gov/20170002582.pdf

Marling, H., \& Emanuelsson, S. (2012). The Markowitz Portfolio Theory (pp. 1-6). http://www.smallake.kr/wp-content/uploads/2016/04/HannesMarling_SaraEmanuelsso $\underline{\text { n_MPT.pdf }}$

Mlbert, P. O. (2010). Corporate Governance of Banks after the Financial Crisis-Theory, Evidence, Reforms (pp. 1-45). ECGI-Law Working Paper. https://papers.ssrn.com/sol3/papers.cfm?abstract_id=1448118

Moloney, N. (2010). Eu Financial Market Regulation after the Global Financial Crisis: “More Europe or More Risks"? Common Market Law Review, 47, 1317-1383. http://www.kluwerlawonline.com/document.php?id=COLA2010058

Naldi, M., \& Flamini, M. (2017). Censoring and Distortion in the Hirschman-Herfindahl Index Computation. Economic Papers: A Journal of Applied Economics and Policy, 36, 401-415. https://doi.org/10.1111/1759-3441.12187

https://www.researchgate.net/publication/319308320_Censoring_and_Distortion_in_t he_Hirschman-Herfindahl_Index_Computation

Naldi, M., \& Naldi, M. (2014). The CR4 Index and the Interval Estimation of the Herfindahl-Hirschman Index: An Empirical Comparison. Hal Archives-Ouvertes. https://hal.archives-ouvertes.fr/hal-01008144 https://doi.org/10.2139/ssrn.2448656

Qi, F., Niu, D.-W., \& Guo, B.-N. (2017). Simplification of Coefficients in Differential Equations Associated with Higher Order Frobenius-Euler Numbers. https://www.preprints.org/manuscript/201708.0017/v1 https://doi.org/10.20944/preprints201708.0017.v1

Reynolds, D. (2009). Analyzing Concentration Risk. Algorithmics Software LLC. https://pdfs.semanticscholar.org/0542/e1c0f2ef8ac298a1c22a36e18a31b4fd87d2.pdf

Rhoades, S. A. (1993). The Herfindahl-Hirschman Index (pp. 188-189). St. Louis, MO: Federal Reserve Bank of St. Louis.

https://fraser.stlouisfed.org/files/docs/publications/FRB/pages/1990-1994/33101_19901994.pdf

Semper, J. D. C., \& Beltrn, J. M. T. (2011). Sector Concentration Risk: A Model for Estimating Capital Requirements. Mathematical and Computer Modelling, 54, 1765-1772. https://www.sciencedirect.com/science/article/pii/S0895717710005789 https://doi.org/10.1016/j.mcm.2010.11.086

Tasche, D. (2006). Measuring Sectoral Diversification in an Asymptotic Multi-Factor Framework. Journal of Credit Risk, 2, 33-55. https://arxiv.org/abs/physics/0505142 https://doi.org/10.2139/ssrn.733084

The Binomial Distribution (2018). https://www3.nd.edu/ rwilliam/stats1/x13.pdf

Tognetti, K. (1998). e the EXPONENTIAL-The Magic Number of GROWTH(pp. 1-32). Wollongong: School of Mathematics and Applied Statistics, University of Wollongong. https://www.austms.org.au/Modules/Exp/exp.pdf

Vo, L. H. (2015). Lessons from the 2008 Global Financial Crisis: Imprudent Risk Management and Miss Calculated Regulation. Journal of Management Sciences, 2, 205-222. https://www.researchgate.net/publication/297601761_Lessons_From_The_2008_Globa 1_Financial_CrisisImprudent_Risk_Management_And_Miss_Calculated_Regulation https://doi.org/10.20547/jms.2014.1502104

Waibel, A. (2006). Das Risiko verbriefter Forderungen-Grundlagen, Ratingverfahren und Problemfelder. MA Thesis, Koeln: Universitaet zu Koeln. 
Watt, R., \& Quinto, J. (2003). Some Simple Graphical Interpretations of the Herfindahl-Hirshman Index and Their Implications (pp. 1-29). Working Document Universidad Autnoma de Madrid and Universidad San Pablo CEU.

http://www.idee.ceu.es/Portals/0/Publicaciones/simple-graphical-interpretations-of-He rfindahl-Hirshman-Index.pdf

Yoshizawa, Y., \& Witt, G. (2003). Moody's Approach to Rating Synthetic CDOs (pp. 1-24). Moody's Investors Service.

http://globalriskguard.com/resources/crderiv/Moody\%27s\%20synthetic\%20CDO.pdf 